\title{
HPTLC METHOD FOR THE DETERMINATION OF LUPEOL FROM ANDROGRAPHIS ECHIOIDES LEAVES
}

\author{
S. GURUPRIYA, L. CATHRINE, P. PRATHEEMA
}

Department of Chemistry, Holy Cross College, Tiruchirappalli 620002, TamilNadu, India

Email: gurupriyaonline@gmail.com

Received: 12 Jan 2018 Revised and Accepted: 05 Apr 2018

\begin{abstract}
Objective: A new simple, precise, rapid and selective highperformance thin-layer chromatographic (HPTLC) method has been developed for th e determination of lupeol in methanolic leaves extract of Andrographis echioides.

Methods: As per International Conference on Harmonization (ICH) guidelines we have applied different concentrations of lupeol as standard on HPTLC plates for the quantification of lupeol from the Andrographis echioides leaves. The concentration of standard lupeol was $1 \mathrm{mg} / \mathrm{ml}$.

Results: The retention factor of lupeol was found to be 0.55 . Linearity was obtained in the range of $5000 \mathrm{ng}-10000 \mathrm{ng}$ for lupeol. The developed and validated HPTLC method was employed for lupeol in methanolic leaves extract of Andrographis echioides for standardization of the content of the marker. The linear regression data for the calibration plots showed a good linear relationship with $\mathrm{r}=0.99917$ for lupeol. Satisfactory recoveries of $99.80 \%$ were obtained for lupeol.
\end{abstract}

Conclusion: The results obtained in validation assays indicate the accuracy and reliability of the developed HPTLC method for the quantification of lupeol in methanolic leaves extract of Andrographis echioides.

Keywords: Andrographis echioides, Lupeol, HPTLC (high-performance thin-layer chromatographic) technique

(C) 2018 The Authors. Published by Innovare Academic Sciences Pvt Ltd. This is an open access article under the CC BY license (http://creativecommons.org/licenses/by/4.0/] DOI: http://dx.doi.org/10.22159/ijpps.2018v10i5.24748

\section{INTRODUCTION}

Phytochemical evaluation is one of the tools for quality assessment, which includes preliminary phytochemical screening, chemoprofiling and marker compound analysis using modern analytical techniques. Use of chromatography for standardization of plant products was introduced by the WHO (world health organization) and is accepted as a strategy for identification and evaluation of the quality of plant medicines [1]. HPLC and HPTLC both emerged as an efficient tool for the phytochemical evaluation. HPTLC is a widely accepted technique for its high accuracy, precision and reproducibility of results. In addition, HPTLC has many advantages because of high sample throughput at low operating cost, easy sample preparation, short analysis time and analytical assurance [2-4].

Secondary metabolites are natural products that often have an ecological role in regulating the interactions between plants and their environment. They can be defensive substances, such as phytoalexins and phytoanticipins, antifeedants, attractants and pheromones [5]. The importance of plant secondary metabolites in medicine, agriculture and industry has led to numerous studies on the synthesis, biosynthesis and biological activity of these substances [6]. The terpenes are biosynthetically constructed from isoprene (2-methyl butadiene) units [7]. The $\mathrm{C}_{5} \mathrm{H}_{8}$ isoprenes polymerise and subsequently fix the number and position of the double bonds. The basic molecular formulae of terpenes are thus multiples of $\mathrm{C}_{5} \mathrm{H}_{8}$ [8]. Triterpenes comprise a large number of different types of compounds which may be divided into more important chemical structure families. The main groups of triterpenoids are represented by pentacyclic derivatives of lupeol [9]. The 3-0-acyl-derivatives of lupeol have anti-inflammatory properties and many of them are present in different medicinal plants, as are lupeol acetate and lupeoldocosanoylate in Willughbeia firma [10].

Andrographis echioides belongs to Acanthaceae family, used for various medicinal purposes in South Asia particularly India and China Based on the literature, this plant possess pharmacological properties include antimicrobial activity, anti-inflammatory, diuretic, anthelmintic, analgesic, antipyretic, hepato-protective activities and antioxidant effect. It contains plenty of phytochemical constituents such as flavonoids, flavones, steroids, tannins, carbohydrate, glycosides and alkaloids $[11,12]$. The leaf juice of $A$. echiodies is used to cure fevers. Genus of Andrographis family plants are used to cure various diseases like goiter, liver diseases, fertility problems, bacterial, malarial and fungal disorders [13, 14]. Andrographis echioides boiled with coconut oil is used to decrease the falling and graying of hair [15]. From the leaves extract of Andrographis echioides various chemical constituents were isolated dihydro echioidinin, skullcap avone 12 ' methyl ether, echioidinin, echioidin, skullcap avone 1 and 2'-0-bDglucopyranoside [16]. Some of the other chemical constituents present in the $A$. echioides are more than 17 compounds such as borneol, cyclohexanol 2,4 dimethylphenol, 3,4 altroson, ndeconoicacid, Squalene, vitamin E, Methoprene, 2-nonenlol Oxirane,octyl-, 2, 2cyclopentene-1-undecanoic acid, ketone, 1,5-methylbicyclo [2.1.0] pent-5-yl methyl and 2,5-cyclohexadiene-1,4-dione, 2, 5-dihydroxy-3methyl-6-(1-methyl ethyl) bicycle heptan-3-one [17]. However, no single method was found in the literature to our knowledge to detect lupeol in methanolic extract of leaves of Andrographis echioides. Therefore, the present study aimed to develop a HPTLC method for analysis of lupeol in Andrographis echioides leaves which have not yet been reported. The developed method was optimized and validated in accordance with International Conference on Harmonization (ICH) guidelines. The present study was designed to develop a new simple, precise, rapid and selectiperfohighnce thin-layer chromatographic (HPTLC) method for the determination of lupeol in methanolic leaves extract of Andrographis echioides.

\section{MATERIALS AND METHODS}

\section{Chemicals and reagents}

Lupeol (purity 99\%), was purchased from Sigma-Aldrich, New Delhi. All the chemicals, including solvents such as n-hexane, ethyl acetate, chloroform, methanol, anisaldehyde sulphuric acid reagents $0.5 \mathrm{ml}$ p-anisaldehyde in $50 \mathrm{ml}$ glacial acetic acid and $1 \mathrm{ml}$ conc. sulfuric acid. Heat to $105^{\circ} \mathrm{C}$ until maximum visualization of spots) were of analytical grade and were procured from from E. Merck, India. 


\section{Collection of plant material}

The leaves of Andrographis echioides were collected in the month of may from the mullipatti, pudukkottai, Tamil Nadu, India. The plant was identified and leaves of Andrographis echioides were authenticated and confirmed from Dr. S. John Britto, Director, Rapinat herbarium, St. Joseph College, Tiruchirapalli, and Tamil Nadu for identifying the plants. The voucher specimen number SGP001 (7.06.2017).

\section{Preparation of methanol extracts}

The leaves of Andrographis echioides were washed in running water, cut into small pieces and then shade dried for a week at $35-40^{\circ} \mathrm{C}$, after which it was grinded to a uniform powder of 40 mesh size. The methanol extracts were prepared by soaking $100 \mathrm{~g}$ each of the dried powder plant materials in $1 \mathrm{~L}$ of methanol using a soxhlet extractor continuously for $10 \mathrm{hr}$. The extracts were filtered through whatmann filter paper No. $42(125 \mathrm{~mm})$ to remove all unextractable matter, including cellular materials and other constitutions that are insoluble in the extraction solvent. The entire extracts were concentrated to dryness using a rotary evaporator under reduced pressure. The final dried samples were stored in labeled sterile bottles and kept at $-20^{\circ} \mathrm{C}$. The filtrate obtained was used as sample solution for the further HPTLC analysis [18].

Identification and quantification of lupeol from leaves of Andrographis echioides by HPTLC

\section{Sample preparation}

The HPTLC plates Si $60 \mathrm{~F}_{254}(20 \mathrm{cmX10} \mathrm{cm})$ were purchased from E. Merck (India). Standards of lupeol ( $99 \%$ purity) were purchased from sigma (New Delhi, India). $100 \mathrm{mg} / \mathrm{ml}$ of methanolic extracts of leaves of Andrographis echioides was taken for analysis. The extracts were filtered and vacuum dried at $45^{\circ} \mathrm{C}$. The dried extracts were separately redissolved in $1 \mathrm{ml}$ of methanol and sample of varying concentration (1-5 $\mu \mathrm{l})$ for lupeol were spotted for quantification. 1 $\mathrm{mg}$ of standard lupeol was prepared in $1 \mathrm{ml}$ of chloroform, and different amounts of (5000-10000 ng) lupeol were loaded onto a TLC plate to get the calibration curve [19-22].

\section{Thin layer chromatography}

A Camag HPTLC system equipped with an automatic TLC sampler $\mathrm{ATS}_{4}$, TLC scanner 3 and integrated software Win CATS version 3 was used for the analysis. Samples were washed on a pre-coated silica gel HPTLC plates Si $60 \mathrm{~F}_{254}(20 \mathrm{~cm} \times 10 \mathrm{~cm})$ plate of $200 \mu \mathrm{m}-$ layer thickness, for quantification of lupeol in leaves of Andrographis echioides. The samples and standards were applied on the plate as 8 $\mathrm{mm}$ wide bands with a constant application rate of $150 \mathrm{Nl} \mathrm{s}^{-1}$, with an automatic TLC sampler $\left(\mathrm{ATS}_{4}\right)$ under a flow of $\mathrm{N}_{2}$ gas, $15 \mathrm{~mm}$ from the bottom, $15 \mathrm{~mm}$ from the side, and the space between two spots was $6 \mathrm{~mm}$ in the plate.

\section{Detection and estimation of lupeol}

The linear ascending development was carried out in a camag twin through chamber $(20 \mathrm{~cm} \times 10 \mathrm{~cm})$, which was pre-saturated with a 25 $\mathrm{ml}$ mobile phase, $\mathrm{n}$-Hexane: ethyl acetate $(80: 20 \mathrm{v} / \mathrm{v})$ for lupeolfor30 min, at room temperature $\left(25^{\circ} \mathrm{C} \pm 2^{\circ} \mathrm{C}\right)$ and $50 \pm 5 \%$ relative humidity. The length of the chromatogram run was up to $90 \mathrm{~mm}$. Subsequent to the development; the TLC plate was dried in a current of air, with the help of air dryer, in a wooden chamber with adequate ventilation. The dried plate was dipped into freshly prepared anisaldehyde sulphuric acid reagents. Quantitative estimation of the plate was performed in the absorption-reflection mode at $538 \mathrm{~nm}$, using a slit width $6.00 \mathrm{x}$ $0.45 \mathrm{~mm}$, with data resolution $100 \mu \mathrm{m} / \mathrm{step}$ and scanning speed 20 $\mathrm{mm} / \mathrm{sec}$. The source of radiation utilized was a tungsten lamp emitting continuous visible spectra of $366 \mathrm{~nm}$. Determination of lupeol in methanolic extracts of Andrographis echioides was performed by the external standard method using pure standards. Each was carried out in triplicate $[23,24]$.

\section{Method validation}

This method was validated as per the ICH guidelines (International Conference on Harmonization in 1994, 1996 and 2005), the method validation parameters checked were linearity, precision, accuracy and recovery, limit of detection, limit of quantification, specificity, robustness and ruggedness. All measurements were performed in triplicates [25-27].

\section{Calibration curve and linearity}

The calibration was performed by analysis of working standard solutions of lupeol (5000-10000 ng for leaves of Andrographis echioides) were spotted on precoated TLC plate, using semiautomatic spotter under a nitrogen stream. The TLC plates were developed, dried by hot air and photometrically analyzed as described earlier. The calibration curves were prepared by plotting peak area versus concentration (ng/spot) corresponding to each spot.

\section{Recovery}

To determine the recovery, known concentrations of standards were added to a pre-analyzed sample of leaves of Andrographis echioides. The spiked samples were then analyzed by the proposed HPTLC method and the analysis was carried out in triplicate.

\section{Precision}

A stock solution containing lupeol compound was prepared in chloroform and six $10 \mu \mathrm{l}$ (1000 ng/spot) bands were applied and analyzed by the developed method to determine instrument precision. Six different volumes of same concentration were spotted on a plate and analyzed by the developed method to determine variation arising from the method itself. To evaluate intra-day precision, six samples at three different concentrations $(1000,2000$ and $3000 \mathrm{ng} / \mathrm{spot}$ ) for lupeol were analyzed on the same day. The inter-day precision was studied by comparing assays performed on three different days.

\section{Limit of detection and limit of quantification}

The detection limit (LOD) of an individual analytical procedure is the lowest amount of analyte in a sample which can be detected but not necessarily quantitated as an exact value. LOD was calculated using the following formula

$$
L O D=3.3 * \frac{\text { Standard deviation of they }- \text { intercept }}{\text { Slope of calibration curve }}
$$

The quantification limit (LOQ) of an individual analytical procedure is the lowest amount of analyte in a sample which can be quantitatively determined with suitable precision and accuracy. LOQ was calculated using the following formula,

$$
L O Q=10 * \frac{\text { Standard deviation of they }- \text { intercept }}{\text { Slope of calibration curve }}
$$

\section{Specificity}

The specificity of the method was ascertained by analyzing standard compound lupeol and the compound lupeol is present in the leaves of Andrographis echioides.

\section{Method specifications}

Silica gel $60 \mathrm{~F} 254$ precoated plates $(20 \times 10 \mathrm{~cm})$ were used with $\mathrm{n}$ hexane: ethyl acetate $(80: 20 \mathrm{v} / \mathrm{v})$ for lupeol as the solvent system. The sample was spotted on precoated TLC plates by using Linom at 5 applicator. Ascending mode was used for development of thin layer chromatography. TLC plates were developing up to $80 \mathrm{~mm}$ and scanned in fluorescence mode at $366 \mathrm{~nm}$. The contents of lupeol in the leaves of Andrographis echioides were determined by comparing area of the chromatogram of standard lupeol with a calibration curve of the marker compound of leaves of Andrographis echioides considering the isolated compound to be $100 \%$ pure.

\section{Robustness}

For the determination of the robustness of method chromatographic parameters, such as mobile phase composition and detection wavelength, were intentionally varied to determine their influence on the retention time and quantitative analysis. Intraday variability 
was studied for the sample, by injecting the same concentration of the sample in triplicate and the standard error mean was calculated.

\section{RESULTS}

\section{Optimization of HPTLC chromatographic conditions}

HPTLC fingerprint patterns have been therefore evolved for methanolic extracts of leaves of Andrographis echioides. Lupeol standard was quantitated accurately using silica gel $F_{254}$ HPTLC precoated plates with the mobile phase n-hexane: ethyl acetate (80: 20 $\mathrm{v} / \mathrm{v}$ ), the Rf value was about 0.55 . The chromatographs of lupeol and methanolic extract of leaves of Andrographis echioides are shown in (fig. 1). The Rf value of lupeol was matched with the $\mathrm{Rf}$ value of extract was about 0.55 was shown in peak (fig. 2 (a) and (b)). A terpenoid compound lupeol were identified and isolated by HPTLC techniques.

\section{Validation of HPTLC method}

\section{Calibration curve and linearity}

The calibration curve was prepared by plotting peak area versus concentration (ng/spot) corresponding to each spot (fig. 3). The regression equation and correlation curves for lupeol in leaves of Andrographis echioides were, regression via height $\mathrm{y}=148.075 \mathrm{X}$ and $\mathrm{r}=0.99755 \mathrm{sdv}=0.72$ fig. 3 (a) and regression via area $y=212.106+1730.405 X$ and $r=0.99917 \mathrm{sdv}=0.72$ fig. $3(\mathrm{~b})$.

\section{Accuracy and recovery}

The results showed that the percentage recoveries after sample processing and application were in the range of $99.80 \%$ to 100.10 $\%$ (lupeol) (table 1). The percentage of lupeol in leaves of Andrographis echioides (table 2).

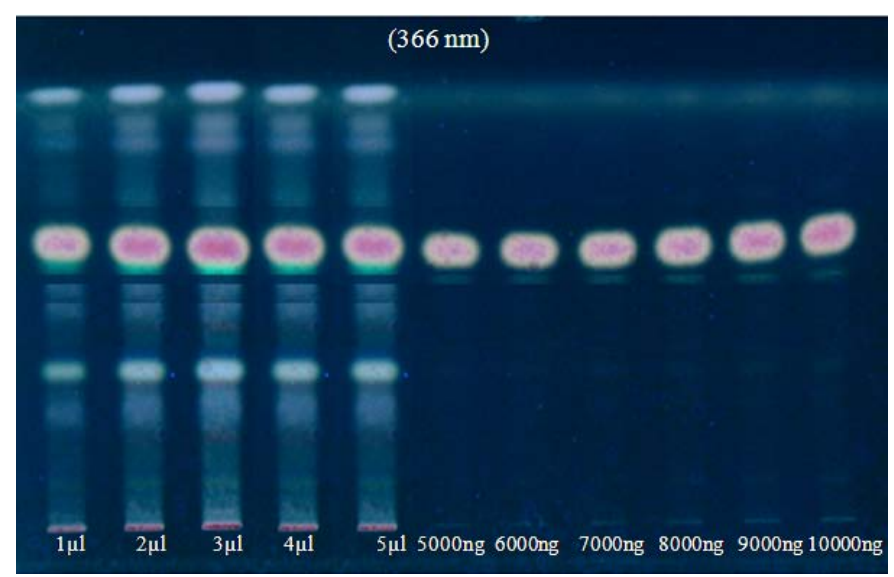

Fig. 1: Quantitative estimation of lupeol in Andrographis echioides leaves
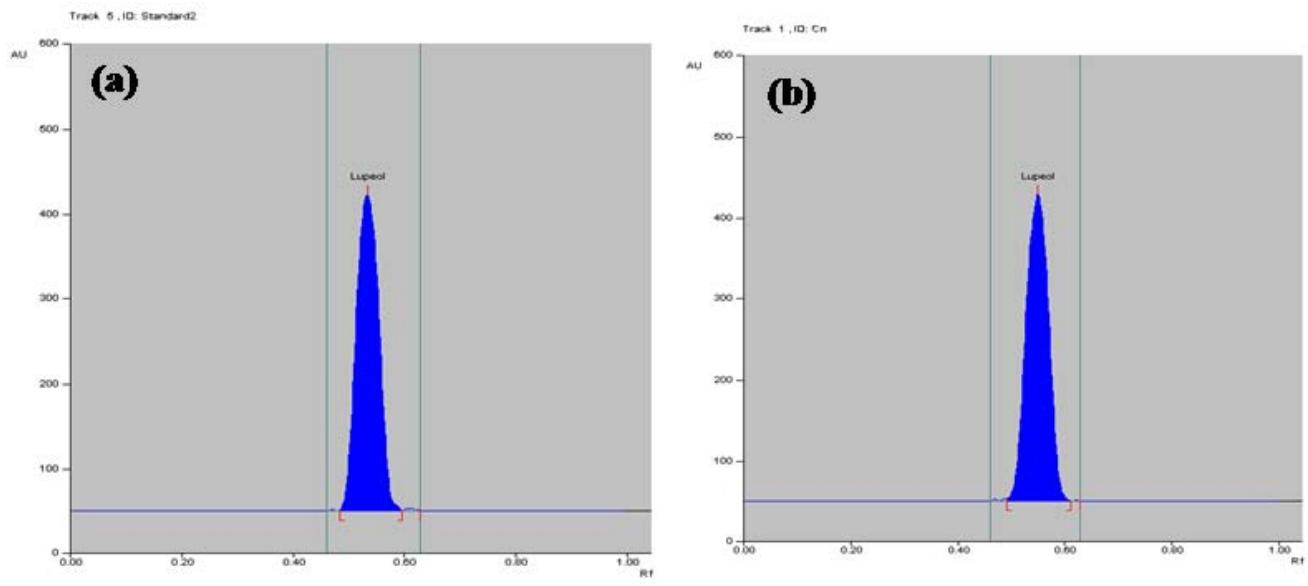

Fig. 2: (a) HPTLC chromatogram of standard lupeol (b) HPTLC chromatogram of lupeol in Andrographis echioides leaves
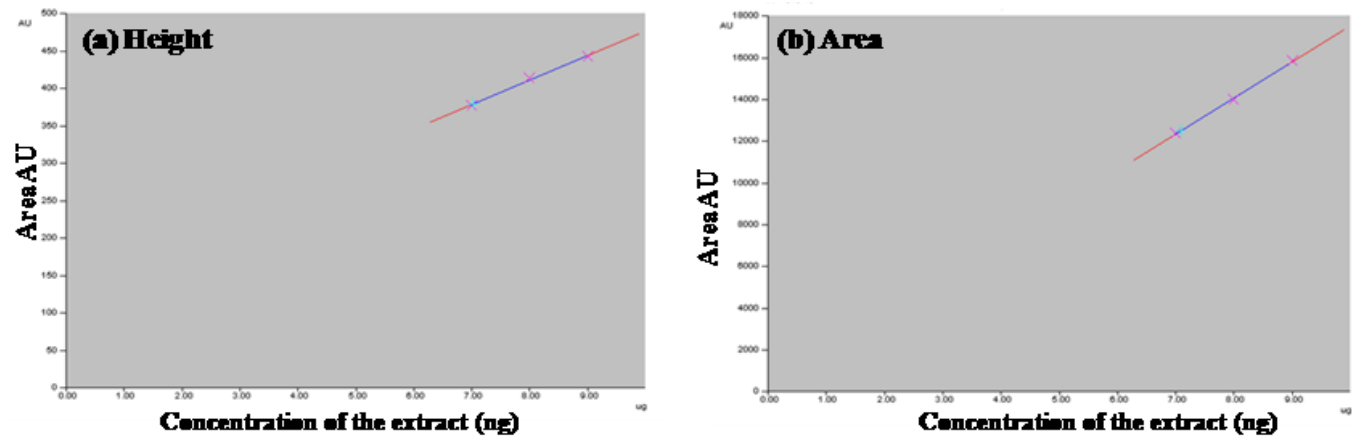

Fig. 3: Linear graph for lupeol in Andrographis echioides in all tracks (concentration vs. area) 


\section{Precision}

The developed method was found to be precise as indicated by percent RSD (Relative Standard Deviation) not more than 1.5 (tables 3 and 4).

\section{Specificity}

It was observed that the other herbal constituents present in the formulations did not interfere with the peak of lupeol. Therefore the method was specific. The spectrum of standard compound lupeol and the corresponding spot present in leaves of Andrographisechioides matched exactly, indicating no interference by the other plant constituents and excipients. The peak purity of lupeol was assessed by comparing the spectra at three different levels like peak start (S), peak apex (M) and peak end (E) positions of the spot. Good correlation $r=0.99917$ and $S D=0.72$ for lupeol were obtained between the standard and sample overlain spectra of lupeol (fig. 4).

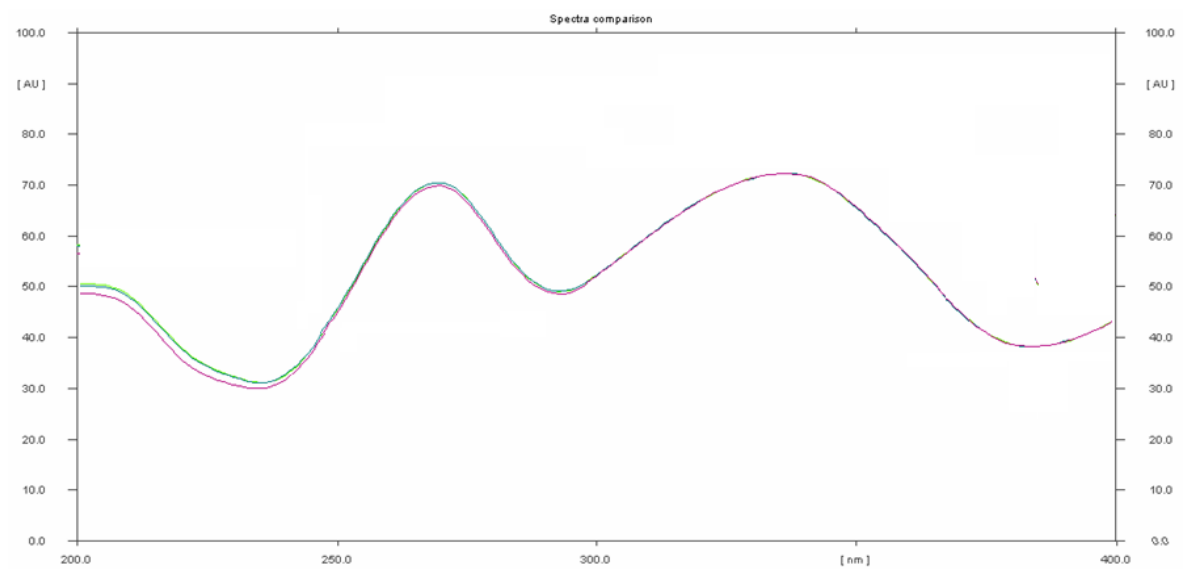

Fig. 4: Spectral comparison of standard lupeol (green colour) and lupeol quantified from Andrographis echioides leaves (pink colour)

Table 1: Recovery study of Lupeol by HPTLC $(n=3)$

\begin{tabular}{lllll}
\hline Compound & $\begin{array}{l}\text { Amount of compound present in the plant material } \\
\text { (mean, } \boldsymbol{\mu g} / \mathbf{1 0 0} \mathbf{~ m g})\end{array}$ & $\begin{array}{l}\text { Amount of standard } \\
\text { added }(\boldsymbol{\mu g})\end{array}$ & $\begin{array}{l}\text { Amount of standard found in } \\
\text { the mixture }(\boldsymbol{\mu g})\end{array}$ & Recovery (\%) \\
\hline Lupeol & 265 & 265 & 520.00 & $100.10 \pm 1.14$ \\
& & 520 & 800.00 & $99.80 \pm 0.93$ \\
\hline
\end{tabular}

$\mathrm{n}$ is number of determination, $\mu \mathrm{g}$ (microgram), $\mathrm{mg}$ (milligram)

Table 2: Amount of Lupeol in Andrographis echioides leaves ( $n=3)$

\begin{tabular}{llll}
\hline Compound & Quantity (mean) (mg/100 mg) & mean \pm SE & CV (\%) \\
\hline Lupeol & 0.265 & $0.265 \pm 0.004$ & 0.72 \\
\hline
\end{tabular}

$\mathrm{n}$ is number of determination, $\mathrm{SE}$ is standard error, $\mathrm{CV}$ is cumulative value

Table 3: Intra-day and inter-day precision of the $\operatorname{method}(n=6)$

\begin{tabular}{|c|c|c|c|c|c|c|c|}
\hline \multirow[t]{2}{*}{ Compound } & \multirow[t]{2}{*}{ Amount (ng/spot) } & \multicolumn{3}{|c|}{ Intra-day precision } & \multicolumn{3}{|c|}{ Inter-day precision } \\
\hline & & Mean area & SD & \%RSD & Mean area & SD & \%RSD \\
\hline \multirow[t]{3}{*}{ Lupeol } & 1000 & 2480.50 & 1.83 & 0.08 & 2490.30 & 3.57 & 0.14 \\
\hline & 2000 & 4900.45 & 2.81 & 0.05 & 4900.62 & 5.88 & 0.16 \\
\hline & 3000 & 7340.40 & 1.48 & 0.02 & 7338.02 & 4.80 & 0.06 \\
\hline
\end{tabular}

$\mathrm{n}$ is number of determination, $\mathrm{SD}$ is standard deviation, RSD is relative standard deviation

Table 4: Summary of validation parameter

\begin{tabular}{|c|c|c|}
\hline \multicolumn{2}{|c|}{ Parameters } & \multirow[t]{2}{*}{ Lupeol } \\
\hline Line & & \\
\hline & Range & $5000-10000 \mathrm{ng}$ \\
\hline & Correlation coefficient & 0.99755 \\
\hline (a) & Height & 0.99917 \\
\hline & Area & 0.55 \\
\hline & Rf value & \\
\hline \multicolumn{3}{|c|}{ Precision (\%RSD) } \\
\hline & Instrument precision (CV\%, $n=6)$ & 1.34 \\
\hline & Method precision $(\mathrm{CV} \%, \mathrm{n}=6)$ & 2.40 \\
\hline LOD & (spot) & 120 \\
\hline LOQ & (spot) & 435 \\
\hline Spe & & Specific \\
\hline Rob & & Robust \\
\hline Rug & less (\%RSD) & 0.9512 \\
\hline
\end{tabular}

$\mathrm{n}$ is a number of determination, RSD is a relative standard deviation, CV is cumulative value, LOD is Limit of detection, LOQ is Limit of quantification, $\mathrm{Rf}$ is retention factor. 


\section{Limit of detection and limit of quantification}

The limit of detection was found to be $120 \mathrm{ng} / \mathrm{spot}$ for lupeol while the limit of quantification was found to be $435 \mathrm{ng} / \mathrm{spot}$ for lupeol (table 4).

\section{Robustness}

Robustness tests examine the effect of the operational parameters on the analysis results. By introducing small changes in mobile phase composition, the results indicated that the method was robust (table 5).

Table 5: Robustness of the method $(n=6)$

\begin{tabular}{lll}
\hline Compound & Amount (ng/spot) & Mobile phase \\
\hline Lupeol & 1000 & n-hexane: Ethyl acetate $(80: 20 \mathrm{v} / \mathrm{v})$ \\
& & n-hexane: Ethyl acetate $(70: 30 \mathrm{v} / \mathrm{v})$ \\
& & n-hexane: Ethyl acetate $(90: 10 \mathrm{v} / \mathrm{v})$ \\
\hline
\end{tabular}

$\mathrm{n}$ is number of determination, RSD is relative standard deviation

\section{Ruggedness of the method}

It expresses the precision within laboratories variations like different days, different analyst, and different equipment. Ruggedness of the method was assessed by spiking the standard 6 times in two different days with the different analyst (table 4).

\section{DISCUSSION}

TLC or HPTLC is primarily used as an inexpensive method for separation, qualitative identification, or semi-quantitative visual analysis of samples. Accordingly, TLC is often described as a pilot method for HPLC [28]. However, recent reviews show that the TLC and HPTLC techniques can be used to solve many qualitative and quantitative analytical problems in a wide range of fields, including medicine, pharmaceuticals, chemistry, biochemistry, food analysis, toxicology and environmental analysis [29]. The use of TLC/HPTLC has expanded considerably due to the development of forced flow (FF) and gradient TLC methods, improved stationary and mobile phase selection, as well as new methods of quantitation methods [30]. The chromatographic method was validated according to ICH guidelines. Linearity study indicated that area was directly proportional to concentration $\left(r^{2} 0.999\right)$ and that the developed method was linear. Quantitation was achieved with linear calibration curves at concentration range of 5000-10000 ng/spot indicating that the method is sensitive. \% RSD for repeatability and reproducibility study was less than 1.5 showing that the method was precise. In roubustness study, \% RSD was found to be less than 1.5 indicating that small changes in process parameters, such as time from development to scanning and mobile phase ratio did not show any major changes in results. The LOD, LOQ were found to be at $120 \mathrm{ng} / \mathrm{spot}$ and 435 $\mathrm{ng} /$ spot respectively. Recovery study was carried out at concentration level of $265 \mu \mathrm{g} / \mathrm{spot}$. Mean \% recovery was found to be 99.8. The proposed HPTLC method was found to be specific.

Previous study has reported that quantitative analysis of andrographolide in Andrographis paniculata herb samples by highperformance thin-layer chromatographic methods [31]. The whole plant of Andrographis echioides contains more number of phytoconstituents (alkaloids, flavonoids, glycosides, phenols, phytosterols, proteins, saponins, tannins and triterpenoids, volatileoils, amino acid, cardiac glycosides, gums and phytosteroids) that are extracted using various solvents depending upon the polarity of these compounds [32,33]. Lupeol, a triterpene compound has been isolated from Crataeva nurvala by HPTLC and also showed antioxaluric and anticalciuric effects in rats against hydroxyprolineinduced hyperoxaluria [34]. The earlier investigators isolated lupeol from the methanol extract of stem bark of Grewia titiaefolia and evaluated the cytotoxic properties on in vitro cell lines [35]. Recently, the isolation of andrographolide, 14-deoxyandrographolide, 14-deoxy12-hydroxyandrographolide, $\beta$-sitosterol, stigmasterol and chlorophyll a, $\beta$-sitosterol, stigmasterol, 5,2'-dihydroxy-7,8dimethoxyflavone, long chain transcinnamateesters and $\beta$-sitosteryl fatty acid esters, $\beta$-sitosterol,monogalactosyl diacylglycerols, lupeol, and triacylglycerols from the pods; and 14-deoxy andrographolide of A. paniculata [36].

The presented study clearly gave evidence of the bioactive quantitative of lupeol in methanolic extracts of leaves of
Andrographis echioides for the first time. The developed HPTLC method for the quantification of above lupeol compounds is simple, precise, specific, sensitive, and accurate. Further, this method can be effectively used for routine quality control of herbal materials as well as formulations containing any or both of these compounds.

\section{CONCLUSION}

In conclusion, an HPTLC method has been developed with some modifications and it can be used for the quantitative determination of lupeol in methanolic extract leaves of Andrographis echioides; its main advantages are its simplicity, accuracy and selectivity. The average recovery values of lupeol were found to be about $99.80 \%$, which showed the reliability and suitability of the method. This method could also be used for the estimation of these compounds in other herbal preparations and might be useful for standardization purposes.

\section{ACKNOWLEDGEMENT}

S. G acknowledges Dr. S. John Britto, Director, rapinat herbarium, St. Joseph College, Tiruchirapalli, Tamil Nadu for identifying the plants. S. G acknowledges Assistant Professor, DR. L. Cathrine of Holy Cross College, Tiruchirapalli, Tamil Nadu for constant support for this research.

\section{AUTHORS CONTRIBUTIONS}

All author contribute equally to this manuscript

\section{CONFLICTS OF INTERESTS}

The authors declare that they have no conflict of interest. It has not been published elsewhere. That it has not been simultaneously submitted for publication elsewhere. All authors agree to the submission to the journal.

\section{REFERENCES}

1. Dhalwal K, Shinde VM, Mahadik KR, Kakasaheb RM. Optimization and validation of reverse phase HPLC and HPTLC method for simultaneous quantification of vasicine and vasicinone in Sida species. Med Plants Res 2010;4 Suppl 13:1289-96.

2. Di X, Chan KKC, Leung HW, Huie CW. Fingerprint profiling of acid hydrolyzates of polysaccharides extracted from the fruiting bodies and spores of Lingzhi by high--performance thin-layer chromatography. J Chromatogr A 2003;1018:85-9.

3. Larsen T, Axelsen J, Ravn HW. Simplified and rapid method for extraction of ergosterol from natural samples and detection with quantitative and semi-quantitative methods using thin layer chromatography. J Chromatogr A 2004;1026:301-4.

4. Suthar AC, Banavaliker MM, Biyani MK, Priyadarsini Indira K, Sudarsan V, Mohan HA. High-performance thin layer chromatography method for quantitative estimation of lupeol in Crataeva nurvala. Indian Drugs 2001;38 Suppl 9:474-8.

5. Hanson JR. The biosynthesis of secondary metabolites. In Natural Products, the secondary Metabolites; 2003. p. 112-21.

6. Gershenzon J, Kreis W. Biosynthesis of monoterpenes, sesquiterpenes, diterpenes, sterols, cardiac glycosides and steroid saponins. In Biochemistry of Plant Secondary Metabolites. Annual Plant Review; 1999. p. 222-99. 
7. Ruzicka L. The isoprene rule and the biogenesis of terpenic compounds. Experimentia 1953;9:357-67.

8. Gershenzon J, Dudareva N. The function of terpene natural products in the natural world. Nat Chem Biol 2007;3:408-14.

9. Patocka J. Biologically active pentacyclic triterpenes and their current medicine signification. J Appl Biomed 2003;1:7-12.

10. Subha dhirasakul S, Takayama H, Kitajima FM, Aimi NF. Triterpenoids from thai medicinal plant. Willughbeia firma. Natural Med 2000;54:155-7.

11. Ankita K, Handique A. Brief overview on Andrographis Paniculata (Burm. f) Nees, A High valued medicinal plant: boon over synthetic drugs. Asian J Sci Technol 2010;6:113-8.

12. Shanker AS, Lalit Kumar Tyagi, Mahendra S, Ch V Ra. Herbal medicine for market potential in india: an overview. Academic J Plant Sci 20081 Suppl 2:26-36.

13. Kirtikar. In: Indian Medicinal Plants. 3. New Delhi: Periodical Experts; 2007.

14. Zulfkar LQ, Beena J, Anandan R, Mohammed RU. Antibacterial activity of ethanol extracts of Indoneesiella echioides evaluated by the filter paper disc method. Pak J Pharm Sci 2009;22:123-5.

15. Kanchana N, Rubalakshmi. Phytochemical screening and antimicrobial activity of Andrographis echioides(L.) Nees-an indigenous medicinal plant. World J Pharm Pharm Sci 2014;3 Suppl 5:702-10.

16. Jayaprakasam D, Gunasekara B, Bodo. Dihydroechioidinin, aavanone from Andrographis echioides. Phytochemistry 1999;1 Suppl 3:92-7.

17. Nirubama $\mathrm{K}$, Rubalakshmi. Bioactive compounds in Andrographis echioides (L.) Nees. leaves by GC-MS analysis. Int J Curr Res Biosci Plant Biol 2014;1 Suppl 3:92-7.

18. Deepti R, Sushila R, Permender R, Aakash D, Sheetal A, Dharmender R. HPTLC densitometric quantification of stigmasterol and lupeol from Ficus religiosa. Arab J Chem 2015; 8:366-71.

19. Suthar AC, Banavaliker MM, Biyani MK, Priyadarsini Indira K, Sudarsan V, Mohan HA. High-performance thin layer chromatography method for quantitative estimation of lupeol in Crataeva nurvala. Indian Drugs 2001;38 Suppl 9:474-8.

20. Badami S, Gupta MK, Ramaswamy S, Rai SR, Nanjaian M, Bendell DJ, Subban R, et al. Determination of betulin in Grewia titiaefolia by HPTLC. J Separ Sci 2004;27:129-31.

21. Purnima D, Hamrapurkar PK. HPTLC determination of stigmasterol and tocopherol acetate in Leptadenia reticulata and its formulation. J Plan Chromatogr 2007;20 Suppl 3:183-7.

22. Geneva. ICH, Q2A(R1), Validation of Analytical Procedure: Text and Methodology, International Conference on Harmonization Specification, November; 2005. p. 5-10.
23. Ravindra CS, Sanjay BK, Kalaichelvan VK. Phytochemical profile studies on the steroids of methanolic leaf extract of medicinally important plant Holoptelea integrifolia (Roxb.) planch using high-performance thin layer chromatography. Asian J Pharm Clin Res 2014;7:4.

24. Lavanya MS, Gnanamani A, Ilavarasan R. Physico-chemical, phytochemical and high-performance thin layer chromatography analysis of the whole plant of Orthosiphon thymiflorus (Roth.) sleesen. Asian J Pharm Clin Res 2015;8:1.

25. Geneva. ICH, Q2B, Guideline on Validation of Analytical Procedure: Methodology, International Conference on Harmonization; 1996. p. 1-8.

26. Geneva. ICH, Q2A, Text on Validation of Analytical Procedure, International Conference on Harmonization; 1994. p. 1-5.

27. Sarfaraj H, Sheeba F, Mohammad Ali, Sarfaraz Alam, Akhlakquer R, Srivastava AK. Phytochemical investigation and simultaneous estimation of bioactive lupeol and stigmasterol in Abutilon indicum by validated HPTLC method. J Coastal Life Med 2014;2 Suppl 5:394-401.

28. Rozylo JK, Janicka M. Different planar techniques for prediction of solute retention in column liquid chromatography. J Planar Chromatogr 1996;9 Suppl 6:418-24.

29. Weins C, Hauck HE. Advances and developments in thin layer chromatography. LC-GC Int 1996;14 Suppl 6:455-71.

30. Poole CF, Poole SK. Instrumental thin-layer chromatography. Anal Chem 1994;66 Suppl 1:27A-37A.

31. Meenu S, Sharma RG. Identifiaction, purification and quantification of andrographolide from Andrographis paniculata (burm. F.) nees by HPTLC at different stages of life cycle of the crop. J Curr Chem Pharm Sci 1994;3 Suppl 1:23-32.

32. Padma Sarojini D, Manjunatha P, Venkata R. Preliminary phytochemical screening and anthelmintic activity of Andrographis echioides nees. J Pharma Res 2015;5 Suppl 9:4801-3.

33. Ramasubramania R. Pharmacognostical phytochemical and anti-ulcer activity of Andrographis echioides (Acanthaceae). J Pharmacogn Phytochem 2014;3 Suppl 3:39-49.

34. Suthar AC, Banavaliker MM, Biyani MK, Priyadarsini Indira K, Sudarsan V, Mohan H. A high-performance thin layer chromatography method for quantitative estimation of lupeol in Crataeva nurvala. Indian Drugs 2001;38 Suppl 9:474-8.

35. Badami S, Gupta MK, Ramaswamy S, Rai SR, Nanjaian M, Bendell DJ, et al. Determination of betulin in Grewia titiaefolia by HPTLC. J Separation Sci 2004;27:129-31.

36. Maria Carmen, S Tan, Glenn G, Oyong, Chien-Chang Shen, Consolacion Y Ragasa. Secondary metabolites from Andrographis paniculata (Burm. f.) nees. Pharm Lett 2016;8 Suppl 13:157-60. 